\title{
Highly Sensitive Electrochemical Sensing Platform for Hydrazine Detection
}

\author{
Jianmian Deng ${ }^{*}$, Shujun Deng and Yingbo Liu \\ School of Environment and Municipal Engineering, North China University of Water Conservancy \\ and Electric Power, Zhengzhou 450011, China \\ *E-mail: dengdengjd_power@163.com
}

doi: $10.20964 / 2018.04 .38$

Received: 19 December 2017 / Accepted: 13 February 2018 / Published: 6 March 2018

\begin{abstract}
In the present study, the Plectranthus amboinicus leaf extract was employed for the biosynthesis of $\mathrm{ZnO}$ nanoparticles (NPs). Then, a novel electrochemical sensor was fabricated based on the $\mathrm{ZnO} \mathrm{NP}-$ coated glassy carbon electrode (GCE) and used for the detection of the organic pollutant hydrazine. Our proposed sensor showed high electrocatalytic activity, selectivity, sensitivity, and stability towards the determination of hydrazine. The factors for the high activity sensor include an optimal electronic property, a high charge transfer rate, a high electroactive surface area, along with its nanocrystalline nature.
\end{abstract}

Keywords: Hydrazine; Biosynthesis; ZnO NPs; Electrochemical determination; Sensor

\section{FULL TEXT}

(C) 2018 The Authors. Published by ESG (www.electrochemsci.org). This article is an open access article distributed under the terms and conditions of the Creative Commons Attribution license (http://creativecommons.org/licenses/by/4.0/). 